\title{
The Effect of University Teachers' Workplace Spirituality on Employee Engagement: Professional Commitment as Mediator
}

\author{
Jianglin Ke' ${ }^{1}$, Fengju Zhang ${ }^{2}$, Xiaocen Yan ${ }^{3}$, Ya Fu ${ }^{4}$ \\ ${ }^{1}$ Organization and Human Resource Management Department, School of Government, Beijing Normal University, Beijing, China \\ ${ }^{2}$ Corporate Training Center, School of Continuing Education, Pecking University, Beijing, China \\ ${ }^{3}$ School of Government, Beijing Normal University, Beijing, China \\ ${ }^{4}$ Melbourne Business School, The University of Melbourne, Parkville, Australia \\ Email: 18813044808@163.com
}

How to cite this paper: Ke, J. L., Zhang, F. J., Yan, X. C., \& Fu, Y. (2017). The Effect of University Teachers' Workplace Spirituality on Employee Engagement: Professional Commitment as Mediator. Creative Education, 8, 2147-2154.

https://doi.org/10.4236/ce.2017.813145

Received: September 20, 2017

Accepted: October 27, 2017

Published: October 30, 2017

Copyright $\odot 2017$ by authors and Scientific Research Publishing Inc. This work is licensed under the Creative Commons Attribution International License (CC BY 4.0).

http://creativecommons.org/licenses/by/4.0/

\begin{abstract}
The current research on workplace spirituality effect is mainly carried out in the west, lacking evidence of China background and attention to university teachers, although the groups are called soul engineer in China. In order to test the effect of workplace spirituality on employee engagement of Chinese university teachers, this study collected 239 samples by convenient sampling. The results of structural equation model test showed that the workplace spirituality of university teachers had a positive impact on their engagement, in which professional commitment played a partly mediating role. The results suggest that universities should strengthen their spirituality construction through various strategies.
\end{abstract}

\section{Keywords}

Workplace Spirituality, Employee Engagement, Professional Commitment, Chinese University Teachers, Mediating Effect

\section{Introduction and Hypothesis}

In the past 20 years, researchers and practitioners have been paying more and more attention to employee engagement and workplace spirituality (GarciaZamor, 2003; Heaton et al., 2004; Saks, 2011). While the theory develops independently, there is practical evidence of the relationship between spirituality and employee engagement (Saks, 2011). Employee engagement relates to the emotional and spiritual aspects of the individuals in work environment (Saks, 2011), 
and how to meet the higher level of employee needs (Quatro, 2004). Increasing focus on spiritual power and employee engagement is caused by the convergence of many cultural motivations, including the spiritual consciousness of the workplace (Fernando \& Jackson, 2006; Garcia-Zamor, 2003), the exploration of employee significance and purpose (Fry, 2003), related to positive psychology, meaning and health (Kahn, 1990; Schaufeli et al., 2006) and so on.

Employee engagement is an area of great concern to both the industry and the academic community. The concept of employee engagement was first developed by Kahn (1990). Employee engagement has become critical to practitioners and researchers in global competitions. From an empirical point of view, employee engagement also associates with positive organizational outcomes including increased profit margins (Luthans, 2001), job satisfaction and commitment (Saks, 2011). The concept and development of workplace spirituality provide a new perspective for the study of employee engagement. But the current research on workplace spirituality effect is mainly carried out in the west, lacking Chinese background evidence.

Meanwhile, the studies have rarely paid attention to university teachers, although the group are known as the engineer of the human soul and required workplace spirituality. University teachers are the vital scientific research force, while the work pressure and economic income of whom are often disproportionate. Meanwhile university teachers are often under so much pressure that there comes more and more exposure of fraud scandal in recent years. Academic field requires teachers to have lofty professional ethics and devote themselves to the exploration of truth. Under this background, we choose university teachers as subjects and try to inspire them and promote innovation by improving their workplace spirituality.

Based on the above reasons, this study will empirically test the impact of university teachers' workplace spirituality on their engagement, and examine the mediating effect of professional commitment in the relationship between them. The findings will provide suggestions for improving teachers' professional commitment and engagement.

The studies of workplace spirituality are firstly carried out in countries such as Europe and America. Chinese scholars such as Ke et al. (2014) puts forward the three-dimension concept of workplace spirituality in the workplace Chinese context. Ke et al. (2014) argues that workplace spirituality is a sense of heart experience generated by the staff after they identify and integrate the value of work, group and organization and transcend themselves.

Engagement is a continuing mental state in the work experience (Schaufeli et al., 2006; Shuck et al., 2011), which reflects how much one employee is committed to the working role (Kahn, 1990). Kahn (1990) suggests that employee engagement contains many aspects of the work experience including physical, cognitive, and emotional and provides meaning when employees are associated with job roles.

In the field of work, individuals with spiritual power show a higher tendency 
to find important job roles (Karakas, 2010; Tepper, 2003). Marques's (2010) case study on Gallup demonstrates how spiritual power was related to employee engagement, and that many scholars directly established the theory of spiritual power to influence employee engagement and sought the relationship between the two variables by empirical research (Saks, 2011). Spirituality also links to employee engagement as an inherent dimension of character, as its influence on inner growth and changing intuition (Maslach et al., 2001; Shuck et al., 2011) is similar to the way in which character traits affect work (Schaufeli, et al., 2006; Maslach et al., 2001). Swindell (2014) through empirical research found that the individual spirit has a positive effect on the overall staff engagement.

Based on the forgoing, the following is hypothesized:

Hypothesis 1: The workplace spirituality of university teachers has a positive effect on their engagement.

The workplace spirituality is an intrinsic self-awareness (Ashmos \& Duchon, 2000), a positive psychological state of the individual that supports meaningful work and enables individuals to demonstrate their ability and get satisfaction from work. Professional commitments reflect employees' commitment to career. Professional commitment also related to career output (Ballout, 2009). Individuals with a high degree of professional commitment and high career expectation will have a significant investment in occupations (Aryee \& Tan, 1992). Therefore, they will be willing to pay the effort needed to achieve their career goals. Meyer \& Allen (1991) described the commitment as a three-component model: affective commitment, continuance commitment and normative commitment and extended the three dimensions of organizational commitment to the field of professional commitment. According to Milliman et al. (2003), the three dimensions of the workplace spirituality have different effects on the commitment. According to Herzberg's two-factor theory, the workplace spirituality is a self-fulfilling need. Meaningful work, group sense of belonging and the consistence with the organizational values can promote the individual to enhance self-efficacy and work actively. It will also promote employees to develop the love of the job and the willing to continue to engage in the profession, that is to have a high professional commitment. Therefore, individuals with high workplace spirituality of the believe that work is more meaningful, and are more willing to show themselves in the work environment and more loyal to the occupation. They then become more enthusiastic and devoted to professional activities, focus on their own business, and are willing to take it a lifelong commitment to pursue. The following assumptions are made: Based on the forgoing, the following is hypothesized:

Hypothesis 2: Workplace spirituality has a positive effect on professional commitment

Hypothesis 3: Professional commitment effects employee engagement

Hypothesis 4: Professional commitment mediates the relationship between workplace spirituality and employee engagement. 


\section{Method}

\subsection{Sample}

The sample for the study was mostly drawn from universities teachers in Beijing. Out of the questionnaires distributed, 240 copies were returned and 239 of them were valid. The effective response rate is $99.6 \%$. In the valid samples, males accounted for $50.21 \%$ and females $49.79 \%$. As for the age, $21-30$ accounted for $20.08 \%, 31 \%-4028.45 \%, 41 \%-5028.87 \%, 51 \%-6020.92 \%$ and over 60 accounted for $1.67 \%$.

\subsection{Measuring}

Workplace spirituality. The study adopts the three-dimension and27-item scale of workplace spirituality developed by Ke et al. (2014) and measured by Likert six-point scale from "completely disagree" to "completely agree", and the overall alpha is 0.97 .

Employee engagement. The study adopts the three-dimension and17-item scale of employee engagement developed by Schaufeli et al. (2006) and measured by Likert seven-point scale from "never" to "always", and the overall alpha is 0.87 .

Professional commitment. The study adopts the 18-item scale of professional commitment developed by Meyer \& Allen (1991) and measured by Likert seven-point scale from "never" to "always", and the overall alpha is 0.91 .

\section{Results}

\subsection{Descriptive Statistics and Correlation Analysis of Variables}

According to the result of SPSS test, the distribution of all variables were normal and there was not multi-collinearity among the variables. Table 1 shows the mean and standard deviation of the variables. The control variables are gender and age, and the mean and standard deviation of each variable are not abnormal. From the point of correlation between the variables in Table 2, in the relationships between the variables of the main effect variables and their dimensions, including the three dimensions of the workplace spirituality and employee engagement and its three dimensions: vitality, focus and dedication are significantly and positively correlated $(p<.01)$. And the correlation coefficient between workplace spirituality and employee engagement was the highest, which was 0.683 . There are significant positive correlations between the meaningful work dimension of the workplace spirituality and the employee engagement as well as its three dimensions $(p<.01)$. The other two dimensions of the workplace spirituality have the same effects. The relationship between the mediator and the dimensions of the other variables, including employee engagement and professional commitment are all significant $(p<0.01)$. In conclusion, there is a significant positive correlation between the variables and their dimensions of the study, which provides the basis for further analysis. 
Table 1. Means and standard deviations of the variables.

\begin{tabular}{cccc}
\hline & $\mathrm{N}$ & Mean & SD \\
\hline Gender & 239 & 1.50 & 0.501 \\
Age & 239 & 2.56 & 1.083 \\
Workplace Spirituality & 239 & 4.6168 & 0.88066 \\
Employee Engagement & 239 & 5.2703 & 1.02428 \\
Professional Commitment & 239 & 5.3203 & 1.20837 \\
\hline
\end{tabular}

Table 2. Descriptive statistics and correlation analysis of variables.

\begin{tabular}{cccccccccc}
\hline & 1 & 2 & 3 & 4 & 5 & 6 & 7 & 8 & 9 \\
\hline 1.Workplace Spirituality & 1 & & & & & & & \\
2.Meaningful Work & $.863^{* *}$ & 1 & & & & & & & \\
3.Sense of Community & $.913^{* *} .681^{* *}$ & 1 & & & & & \\
4.Alignmentwith Organizational Values & $.908^{* *} .662^{* *} .762^{* *}$ & 1 & & & & & \\
5.Employee Engagement & $.660^{* *} .658^{* *} .602^{* *} .581^{* *}$ & 1 & & & & \\
6.Vitaity & $.619^{* *} .588^{* *} .566^{* *} .513^{* *} .957^{* *}$ & 1 & & & \\
7.Dedication & $.603^{* *} .608^{* *} .507^{* *} .509^{* *} .847^{* *} .709^{* *}$ & 1 & & \\
8.Focus & $.613^{* *} .584^{* *} .513^{* *} .561^{* *} .802^{* *} .646^{* *} .651^{* *}$ & 1 & \\
9.Professional commitment & $.487^{* *} .432^{* *} .447^{* *} .415^{* *} .490^{* *} .459^{* *} .440^{* *} .395^{* *}$ & 1 \\
\hline
\end{tabular}

Notes: $\mathrm{N}=239 ;{ }^{* *} \cdot P=0.01 ;{ }^{*} \cdot P=0.05$.

\subsection{The Path Analysis of Workplace Spirituality on Employee Engagement}

The study used AMOS 21 to verify the structural relationship among latent variables. The results in Table 3 indicate the model is reasonable, so the intermediary model of professional commitment can be accepted. Figure 1 is the ultimate complete standard resolution of the model. From the results of the model fitting, the coefficient of workplace spirituality and employee engagement reached $0.49(p<0.001)$. The coefficient of workplace spirituality and professional commitment reached 0.49 ( $p<0.001)$. The coefficient of professional commitment and employee engagement reached $0.35(p<0.001)$. The first three hypothesizes are verified. In addition, the test results show that professional commitment plays an intermediary role, supporting $\mathrm{H} 4$.

From Table 4, it can be inferred that the correlations of workplace spirituality and professional commitment and workplace spirituality and employee engagement are both significantly positive $(p<0.01)$ after bringing professional commitment as the intermediary variable. Professional commitment and employee engagement are also significantly correlated $(p<0.01)$. The results show that professional commitment partly mediates the relationship between workplace spirituality and employee engagement. 
Table 3. Fit index of the model.

\begin{tabular}{cccccccc}
\hline$\chi^{2}$ & $\mathrm{df}$ & $\chi^{2} / \mathrm{df}$ & RMR & GFI & CFI & IFI & RMESA \\
\hline 44.127 & 24 & 1.839 & 0.121 & .939 & .936 & .938 & 0.059 \\
\hline
\end{tabular}

Table 4. Models and regression coefficients.

\begin{tabular}{ccccc}
\hline & Estimate & S.E. & C.R. & P \\
\hline Professional Commitment $\leftarrow$ Workplace Spirituality & .990 & .131 & 7.548 & $* * *$ \\
Employee Engagement $\leftarrow$ Workplace Spirituality & .605 & .133 & 4.543 & $* * *$ \\
Employee Engagement $\leftarrow$ Professional Commitment & .259 & .064 & 4.039 & $* * *$ \\
Meaningful Work $\leftarrow$ Workplace Spirituality & 1.000 & & & $* * *$ \\
Sense of Community $\leftarrow$ Workplace Spirituality & 1.249 & .081 & 15.501 & $* * *$ \\
Focus $\leftarrow$ Employee Engagement & 1.000 & & & $* * *$ \\
Vitality $\leftarrow$ Employee Engagement & .979 & .076 & 12.812 & $* * *$ \\
Alignment with Organizational Values $\leftarrow$ Workplace & 1.359 & .079 & 17.303 & $* * *$ \\
$\quad$ Spirituality & 1.121 & .079 & 14.243 & $* * *$ \\
Dedication $\leftarrow$ Employee Engagement & & & &
\end{tabular}

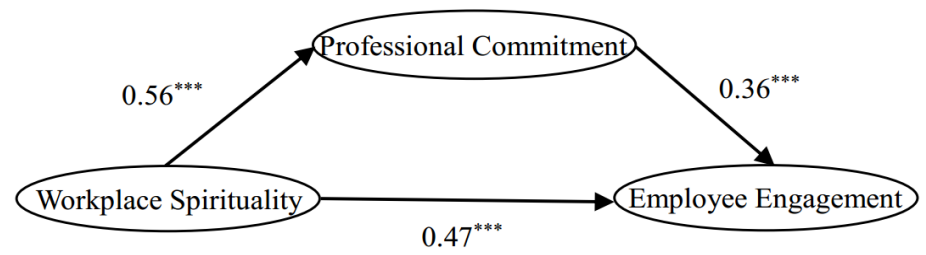

Figure 1. The SEM of the study.

\section{Discussion}

\subsection{Management Implications}

In recent 20 years, scholars have paid increasing attention on spirituality, spiritual power and workplace spirituality. The scholars not only research the concepts and dimensions but also the antecedents and outcomes. This study redefines the concept of workplace spirituality and the employee engagement. By exploring the localization mechanism of the workplace spirituality, the study makes up for the lack of existing research in the West. The study selects the university teachers as study object and the workplace spirituality antecedents. University teachers are a special group, facing research pressure, interpersonal relationships and many other issues. While many organizations take engagement as evaluating indicator to assess employees' behavior and improve organizational performance. Nowadays, universities pay much attention to scientific research behavior and innovative performance. Workplace spirituality of universities teachers will influence their engagement, and then affect research performance and organizational performance.

This study explores the relationship between workplace spirituality and the engagement of the university teachers, which is helpful to explain the inner spirit 
of the teachers, to pay attention to the teachers' psychology, to improve the teachers' incentive, to enhance the teachers' professional commitments and to enhance the university research performance and so on. It is essential to enhance the engagement so as to enhance the scientific research performance. This study proves that universities can enhance the workplace spirituality and employee engagement of university teachers from the aspects of meaningful work, organizational values and so on. In addition, the practice of the workplace spirituality also helps to improve the inner communication of the university, to enhance the level of trust between teachers, to enhance the teachers' satisfaction and sense of belonging, reduce the teacher's sense of alienation and turnover rate, thereby increasing their contribution to the organization.

\subsection{Limitations and Directions for Future Research}

This study also has some limitations. First of all, the relevant research methods of measurement methods need to be improved. Most scales adopted in this study are developed in foreign countries, and the reliability of the scales are all more than 0.8 . The other two scales except workplace spirituality are translated from original English literature, which may bring deviation to measurement result because of cultural differences. Secondly, as for the representativeness of samples, the study finally collected 239 samples which met data analysis requirements. However, the samples are mainly from the Beijing area, and the sample representativeness needs to be improved. In the future, researchers can adopt native scale to improve the reliability of the findings by collecting data from multiple regions to verify the relationship between variables.

\section{Fund}

Project: NSFC 71102020

\section{References}

Aryee, S., \& Tan, K. (1992). Antecedents and Outcomes of Career Commitment. Journal of Vocational Behavior, 40, 288-305.

Ashmos, D. P., \& Duchon, D. (2000). Spirituality at Work: A Conceptualization and Measure. Journal of Management Inquiry, 9, 134-145. https://doi.org/10.1177/105649260092008

Ballout, H. I. (2009). Career Commitment and Career Success: Moderating Role of Self-Efficacy. Career Development International, 14, 655-670. https://doi.org/10.1108/13620430911005708

Fernando, M., \& Jackson, B. (2006). The Influence of Religion-Based Workplace Spirituality on Business Leaders' Decision-Making: An Inter-Faith Study. Journal of Management and Organization, 12, 23-39. https://doi.org/10.1017/S1833367200004144

Fry, L. W. (2003). Toward a Theory of Spiritual Leadership. The Leadership Quarterly, 14, 693-727.

Garcia-Zamor, J.-C. (2003). Workplace Spirituality and Organizational Performance. Public Administration Review, 63, 355-363. https://doi.org/10.1111/1540-6210.00295 
Heaton, D. P., Schmidt-Wilk, J., \& Travis, F. (2004). Constructs, Methods, and Measures for Researching Spirituality in Organizations. Journal of Organizational Change Management, 17, 62-82. https://doi.org/10.1108/09534810410511305

Kahn, W. A. (1990). Psychological Conditions of Personal Engagement and Disengagement at Work. Academy of Management Journal, 33, 692-724. https://doi.org/10.2307/256287

Karakas, F. (2010). Spirituality and Performance in Organizations: A Literature Review. Journal of Business Ethics, 94, 89-106. https://doi.org/10.1007/s10551-009-0251-5

Ke, J. L., Sun, J. M., \& Wang, J. (2014). Development and Validation of the Workplace Spirituality Scale. Chinese Journal of Clinical Psychology, 5, 826-830.

Luthans, F. (2001). Employee Engagement and Manager Self-Efficacy: Implications for Managerial Effectiveness and Development. Journal of Management Development, 21, 376-387. https://doi.org/10.1108/02621710210426864

Marques, J. (2010). Spiritual Considerations for Managers: What Matters Most to Workforce Members in Challenging Times. Journal of Business Ethics, 97, 381-390. https://doi.org/10.1007/s10551-010-0514-1

Maslach, C., Schaufeli, W. B., \& Leiter, M. P. (2001). Job Burnout. Annual Review of Psychology, 52, 397-422. https://doi.org/10.1146/annurev.psych.52.1.397

Meyer, J. P., \& Allen, N. J. (1991). A Three-Component Conceptualization of Organizational Commitment. Human Resource Management Review, 1, 61-98.

Milliman, J., Czaplewski, A. J., \& Ferguson, J. (2003). Workplace Spirituality and Employee Work Attitudes: An Exploratory Empirical Assessment. Journal of Organizational Change Management, 16, 426-447. https://doi.org/10.1108/09534810310484172

Quatro, S. A. (2004). New Age or Age Old: Classical Management Theory and Traditional Organized Religion as Underpinnings of the Contemporary Organizational Spirituality Movement. Human Resource Development Review, 3, 228-249. https://doi.org/10.1177/1534484304267830

Saks, A. M. (2011). Workplace Spirituality and Employee Engagement. Journal of Management, Spirituality\& Religion, 8, 317-340. https://doi.org/10.1080/14766086.2011.630170

Schaufeli, W. B., Bakker, A. B., \& Salanova, M. (2006). The Measurement of Work Engagement with a Short Questionnaire: A Cross-National Study. Educational and Psychological Measurement, 66, 701-716. https://doi.org/10.1177/0013164405282471

Shuck, M. B., Rocco, T. S., \& Albornoz, C. A. (2011). Exploring Employee Engagement from the Employee Perspective: Implications for HRD. Journal of European Industrial Training, 35, 300-325. https://doi.org/10.1108/03090591111128306

Swindell, J. R. (2014). Transformational Leadership, Perceived Support, Organizational Commitment, and Union Citizenship Behavior: The Effect of Cultural Diversity(Order No. 3646233)

Tepper, S. (2003). A Model for Care: A Transitions Program Designed to Provide Comprehensive Care in Treating Individuals with Malignant Brain Tumors. Smith College Studies in Social Work, 73, 337-357. https://doi.org/10.1080/00377310309517689 